\title{
Study of Crystallinity Extract Cellulose from Corn Stalk Fiber
}

\author{
Zulkifli I. Tuara ${ }^{12}$, Indah Raya ${ }^{1}$, Maming Gaffar ${ }^{1}$ \\ ${ }^{1}$ Department of Chemistry, Faculty of Mathematics and Natural Sciences, \\ Universitas Hasanuddin, Indonesia, 90245. \\ ${ }^{2}$ Department of Chemistry Education, Faculty of Training, Teacher and Education, \\ Universitas Khairun, Indonesia, 97719. \\ \{zulchemi@gmail.com ${ }^{1}$, indahraya05@gmail.com², maming.gappa@gmail.com³
}

\begin{abstract}
Study of crystallinity Extract Cellulose was carried out. Cellulose extracted by Corn Stalk Fiber using the 'Peracid-Hydroxide-Hypochlorite $(\mathrm{P}-\mathrm{H}-\mathrm{H})^{\prime}$ method and characterized with FTIR and XRD. IR spectra showed strong absorption at $3415.93 \mathrm{~cm}^{-1}$ which is attributed to $\mathrm{O}-\mathrm{H}$ stretching vibration (intermolecular hydrogen bonds), vibrations at $1028.06 \mathrm{~cm}^{-1}$ is assigned for $\mathrm{C}-\mathrm{O}-\mathrm{C}$ stretching which appears almost simultaneously with the vibration located at $993.34 \mathrm{~cm}^{-1}$ (Indicate $\beta-1.4-$ Glycosidic bond by Cellulose). The particle size of Cellulose which is $20.95 \mathrm{~nm}$ and has a crystallinity phase of $66.18 \%$. These results indicate that extract cellulose by the $\mathrm{P}-\mathrm{H}-\mathrm{H}$ method has good material crystallinity.
\end{abstract}

Keywords: Cellulose, Corn Stalk Fiber, Crystallinity.

\section{Introduction}

Cellulose is the most abundant chemical compound in nature, especially as a constituent of plant cells [1]. Cellulose content in fibrous plant parts, which is as a constituent of $40-50 \%$ Wool, $80 \%$ hemp, and $90 \%$ cotton fiber. Cellulose has a chemical structure consisting of $\beta-1.4$ glycosidic bonds [2].

Cellulose which has very compatible, biodegradable, good thermal stability, stable chemical properties, and very cheap [3] to be used as an efficient renewable material, has good crystallinity, and has mechanical properties [4]. Cellulose-based materials, namely nanocrystal cellulose [5][6][7] which have been developed into materials, such as aerogels [8][9][10].

Cellulose was extracted by corn stalk fibers from agricultural waste products in the North Maluku, Indonesia. we used 'Peracid-Hydroxide-Hypochlorite $(\mathrm{P}-\mathrm{H}-\mathrm{H})$ method, contained in a document of the United States Patent 4,400,237 [11], to get a high percentage of extract cellulose. Characterization with FTIR and XRD to determine the functional group, crystal size, and crystallinity phase of extract cellulose. 


\section{Material and Methods}

\subsection{Material Preparation}

Prepared $2 \mathrm{~kg}$ of corn stalk fiber which has been cutting with a size of $1-3 \mathrm{~cm}$, dried in an oven at a temperature of $100{ }^{\circ} \mathrm{C}$ for 16 hours to remove the moisture content in the fiber of the corn stalk to obtain a constant sample weight. Then mashed with a blender and sifted using an 80 mesh sieve to obtain powder of corn stalk fiber.

\subsection{Cellulose extraction}

\subsubsection{Delignification}

As much as 5 grams of fiber powder of corn stalks are put in a $250 \mathrm{ml}$ cup glass with 0.5 $\mathrm{mL}$ of acetic acid added and then heated using a hot plate at $70^{\circ} \mathrm{C}$ while stirring with a magnetic stirrer for 1 hour. Then the addition of $6 \% \mathrm{NaOH}$ as much as $200 \mathrm{~mL}$ the temperature is increased to $80^{\circ} \mathrm{C}$ for 1,5 hours while stirring. Filtering well done using filter paper, then the precipitate is washed with distilled water until a neutral $\mathrm{pH}$ is measured using a $\mathrm{pH}$ meter.

\subsubsection{Bleaching}

Putting the residue into a $250 \mathrm{~mL}$ beaker then adding it with a $0.4 \% \mathrm{NaOCl}$ solution of $150 \mathrm{~mL}$ and heating it at $40^{\circ} \mathrm{C}$ while stirring for 3 hours. The precipitate is filtered and washed with Aquabides until a neutral $\mathrm{pH}$ value obtained. The precipitate is left for 1 hour and taken as cellulose extract.

\subsection{Characterization}

The extract Cellulose was characterized using FTIR SHIMADZU spectrophotometer, to find out the typical functional group of cellulose start at a wavelength on $4000 \mathrm{~cm}^{-1}-400 \mathrm{~cm}^{-1}$ and crystallinity is characterized using XRD-7000 - Shimadzu Scientific Instruments, at wavelength between the angle theta $(\theta) 10^{0}-40^{\circ}$.

\section{Results and Discussion}

\subsection{Extract Cellulose}

Extract Cellulose has been obtained using the method of Peracid-HydroxideHypochlorite $(\mathrm{P}-\mathrm{H}-\mathrm{H})$. The percentage of cellulose was obtained by $89 \%$ which showed that Lignin and hemicellulose were degraded well in the delignification and bleaching process. Acetic acid and $\mathrm{NaOH}$ can increase the release of lignin from cellulose and reduce the degradation process in the cellulose chain [12][11]. 


\subsection{FTIR Characterization}

FTIR characterization based on the cellulose structure shown in Figure 1.

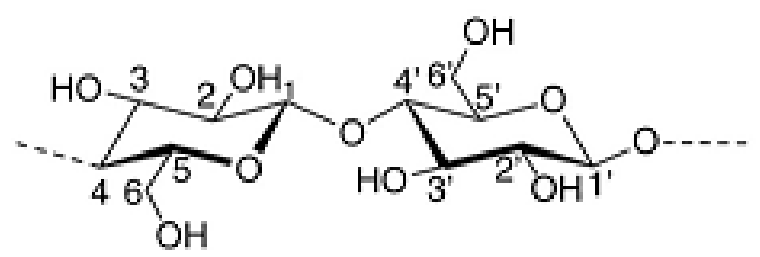

Figure 1. Chemical structure of cellulose. (Kang, H. et al., 2015 on [13])

Cellulose has an absorption area, which is a functional group area at a wavelength of 3500 $\mathrm{cm}^{-1}-1500 \mathrm{~cm}^{-1}$, fingerprint region at a wavelength of $1500 \mathrm{~cm}^{-1}-1000 \mathrm{~cm}^{-1}$, and Aromatic region at a wavelength $<100 \mathrm{~cm}^{-1}$.

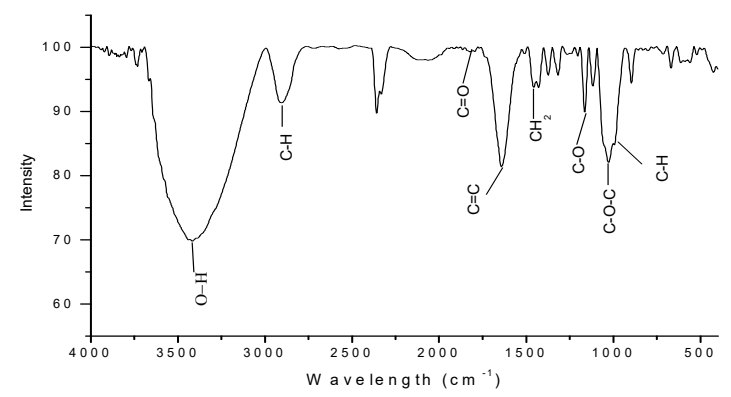

Figure 2. FTIR Cellulose spectra from corn stalk fibers

Table 1. Type of bonding and vibration mode derived from FTIR spectra of Cellulose in figure 2.

\begin{tabular}{lll}
\hline Wavelength $\left(\mathrm{cm}^{-1}\right)$ & Type of bond & Vibration mode \\
\hline 3415.93 & $\mathrm{O}-\mathrm{H}$ & stretching vibration \\
2092.87 & $\mathrm{C}-\mathrm{H}$ & Bending vibration \\
1730.15 & $\mathrm{C}=\mathrm{O}$ & stretching vibration \\
1643.35 & $\mathrm{C}=\mathrm{C}$ & Streching ring \\
1456.26 & $\mathrm{C}-\mathrm{H}$ & $\mathrm{CH}_{2}$ deformation vibration \\
1165 & $\mathrm{C}-\mathrm{O}$ & various bands \\
1028.06 & $\mathrm{C}-\mathrm{O}-\mathrm{C}$ & stretching vibration \\
993.34 & $\mathrm{C}-\mathrm{H}$ & Aromatic plane bending \\
\hline
\end{tabular}

Indicate $\beta-1.4-$ Glycosidic bonds on cellulose in the wavelength region of $1028.06 \mathrm{~cm}^{-1}$ which is simultaneous with a wavelength of $993.34 \mathrm{~cm}^{-1}$. Stretching vibration at wavelength $3415.93 \mathrm{~cm}^{-1}$ shows the interaction between molecules in hydrogen bonds in the chemical structure of cellulose. 


\subsection{XRD Characterization}

The XRD spectra of cellulose have a characteristic that is determined based on the muller index (hkl) that appears at the peak, on 110, 110, 200 [14]., 110,110,102, and 004 [15] Characteristics of cellulose crystals are triclinic and monoclinic [16]. XRD spectra below in figure 3.

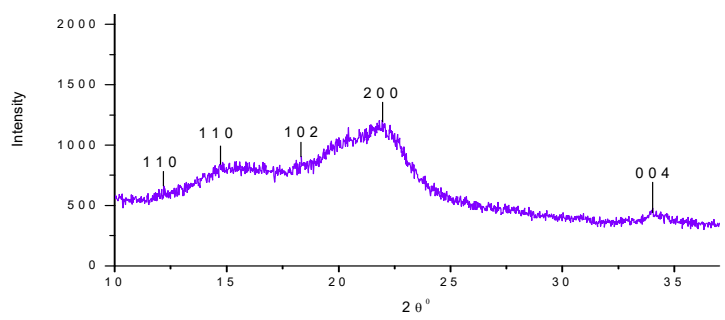

Figure 3. Spectra of XRD Cellulose from corn stalk fiber

Miller indices (hkl) show peaks 110, 110, 102, 200, 400 with angles theta $(\theta) 12.16^{\circ}$, $14.75^{\circ}, 18.36^{\circ}, 21.96^{\circ}, 33.95^{\circ}$ in figure 3 . The small diffraction peaks indicate areas of high crystallinity [17].

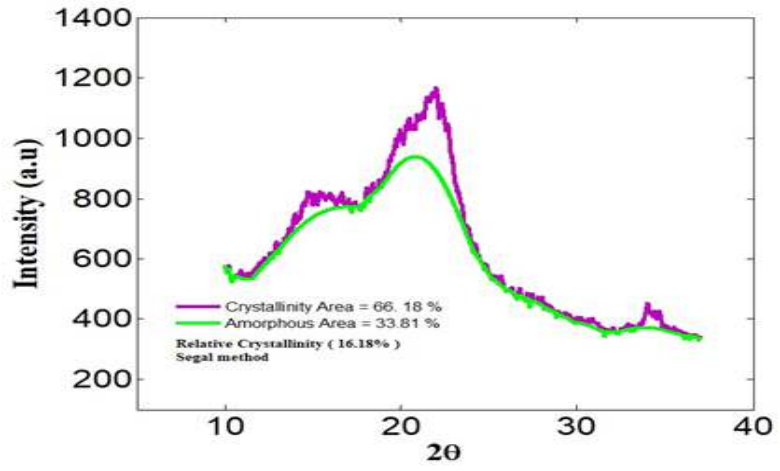

Figure 4. Interpretation of MATLAB to the crystallinity of cellulose

Table 2. Crystal size, crystallinity, Amorphous

\begin{tabular}{lll}
\hline Crystallitesize (nm) & Crystalinity (\%) & Amorphous (\%) \\
\hline $20.95 \mathrm{~nm}$ & 66.18 & 33.81 \\
\hline
\end{tabular}

Crystallinity and Amorphous cellulose areas shown in Table 2 are calculated using the MATLAB program (Operating by Department of Physic, Hasanuddin University, Makassar, Indonesia) on figure 4. Relativity of crystallinity with the Segal method is $16.38 \%$. Crystallinity Relative has a low percentage indicating intermolecular force in the cellulose structure is a very strong.

\section{Conclusion}

We studied of crystallinity of cellulose and characterization with FTIR and XRD. MATLAB program used to determine crystallinity and amorphous on cellulose. These result we have a percentage of cellulose is very high and has been good crystallinity properties. 


\section{Acknowledgements}

This research was supported by the Inorganic research center, Hasanuddin University, Makassar, Indonesia. We thank our colleagues from Department of Physic to calculated with MATLAB programs in this research.

\section{References}

[1] F. He, W. Yang, X. He, and X. Zhang, "In-situ synthesis and structural characterization of cellulose-silica aerogels by one-step impregnation," J. non crystalin solid, vol. 488, pp. 36-43, 2018.

[2] A. Azubuike, Chukwuemeka and Okhamafe, "Physicochemical, spectroscopic and Thermal properties of Microcrystalline Cellulose derived from Corn cobs," IJROA, vol. 9, pp. 1-7, 2012.

[3] L.-Y. Long, Y. Weng, and Y.-Z. and Wang, "Cellulose Aerogels: Synthesis, Applications, and Prospects," Polymers (Basel)., vol. 10, pp. 6-23, 2018.

[4] S. Yang, S., Lu, X., Zhang, Y., Xu, J., Xin, J., and Zhang, "Separation and characterization of cellulose I material from corn straw by low-cost polyhydric protic ionic liquids," Cellulose, vol. 25, pp. 3241-3254.

[5] G. Tingaut, P., Zimmermann, T., and Sebe, "Cellulose nanocrystals and microfibrillated cellulose as building blocks for the design of hierarchical functional materials," J. Mater. Chem, vol. 22, pp. 20105-20111.

[6] M. J. Lewis, L., Derakhshandeh, M., Hatzikiriakos, S.G., Hamad, W.Y., and MacLachlan, "Hydrothermal Gelation of Aqueous Cellulose Nanocrystal Suspensions," Biomacromolecules, vol. 17, pp. 2747-2754, 2016.

[7] E. J. Schyrr, B., Pasche, S., Voirin, G., Weder, C., Simon, Y.C., dan Foster, "Biosensors Based on Porous Cellulose Nanocrystal-Poly(vinyl Alcohol) Scaffolds," ACS Appl. Mater. Interfaces, vol. 6, p. 12674-12683, 2014.

[8] M. J. Xu, Y., Dai, Y., Nguyen, T., Hamad, W.Y., and MacLachlan, "Aerogel materials with periodic structures imprinted with cellulose nanocrystals," rsc.li/nanoscale, vol. 10, pp. 3805-3812, 2018.

[9] E. D. Osorio, D. A., Seifried, B., Moquin, P., Grandfield, K., and Cranston, "Morphology of cross-linked cellulose nanocrystal aerogels: cryo-templating versus pressurized gas expansion processing," J Mater Sci, vol. 53, pp. 9842-9860, 2018.

[10] J. Buesch, C., Smith, S.W., Eschbach, P., Conley, J. F., and Simonsen, "No Title," Biomacromolecules, vol. 17, pp. 2956-2962, 2016.

[11] D. W. Horst Kriger, F. and H. U. S. Berndt, and Rodenbach, "PROCESS FOR BLEACHING CELLULOSE WITH ORGANC PERACID," United States Pat., vol. 4,400,237, pp. 1-6, 1983.

[12] L. Yu, M., Han, Y., Li, J., and Wang, "Magnetic carbon aerogel pyrolysis from sodium carboxymethyl cellulose/sodium montmorillonite composite aerogel for removal of organic contamination," J. Porous Mater, vol. 25, pp. 657-664, 2017.

[13] S. Nesic, Aleksandra and Seslija, "The Influence of nanofillers on Physical-Chemical Properties of Polysaccaride-Based Film Intended for Food Packaging," Food Packag., vol. 19, pp. 637-697, 2017.

[14] G. Gundus, A. Kiziltas, E. Kiziltas, and A. Gencer, "production of Bacterial Cellulose Fibers in The Presence of Effective Microorganism," J. Nat. fibers, pp. 1-9, 2018.

[15] A. Thygensen, J. Oddershede, and H. and Lilholt, "On the determination of Crystallinity and cellulose content in plant fibres," Cellulose, vol. 12, pp. 563-576, 
2005.

[16] R. Moon, A. Martini, J. Nairu, J. Simonsen, and A. Youngblood, "Cellulose nanomaterial review:structure, properties and nanocomposites," Chem Soc Res, vol. 40, pp. 3941-3994, 2011.

[17] D. Tahir, S. Ilyas, B. Abdullah, B. Armynah, K. Kim, and and H. J. Kang, "Modification in electronic, structural, and magnetic properties based on composition of composites Copper (II) Oxide (CuO) and Carbonaceous material," Mater. Res. Express, vol. 6, 2018. 